\title{
Bank Runs and Institutions: The Perils of Intervention
}

\author{
Huberto M. Ennis \\ Research Department \\ Federal Reserve Bank of Richmond \\ Huberto.Ennis@rich.frb.org \\ Todd Keister \\ Research and Statistics Group \\ Federal Reserve Bank of New York \\ Todd.Keister@ny.frb.org
}

August 5, 2008

\begin{abstract}
Governments typically respond to a run on the banking system by temporarily freezing deposits and by rescheduling payments to depositors. Depositors may even be required to demonstrate an urgent need for funds before being allowed to withdraw. We study ex post efficient policy responses to a bank run and the ex ante incentives these responses create. Given that a run is underway, the efficient response is typically not to freeze all remaining deposits, since this would impose heavy costs on individuals with urgent withdrawal needs. Instead, (benevolent) government institutions would allow additional withdrawals, creating further strain on the banking system. We show that when depositors anticipate these extra withdrawals, their incentive to participate in the run actually increases. In fact, ex post efficient interventions can generate the conditions necessary for a self-fulfilling run to occur.
\end{abstract}

Forthcoming in the American Economic Review. We thank Roberto Chang, Doug Diamond and seminar participants at Rutgers University, the Federal Reserve Bank of Richmond, Universidad de Alicante, Universidad de San Andrés, the Society for Economic Dynamics meetings, the Midwest Macro meetings, the North American Meeting of the Econometric Society, the Cornell-Penn State macroeconomics workshop, and the SAET conference in Vigo, Spain, for helpful comments. The views expressed herein are those of the authors and do not necessarily reflect the position of the Federal Reserve Bank of New York, the Federal Reserve Bank of Richmond, or the Federal Reserve System. 


\section{Introduction}

We study ex post efficient policy responses to a run on the banking system and the ex ante incentives these responses give to depositors. We focus primarily on system-wide runs, where depositors rush to withdraw their funds from all banks in the economy simultaneously. Argentina experienced such a run in the last two days of November 2001, with total deposits in the banking system falling by more than 2 billion (U.S.) dollars, or nearly 3\%, on the second day of the run alone. ${ }^{1}$ Such runs were a common occurrence in the United States in the late 19th and early 20th centuries and have also occurred in recent times in several developing countries, including Brazil in 1990 and Ecuador in 1999.

A widespread bank run invariably provokes some intervention by the government and/or central bank. A wide range of policy responses are possible and, in practice, the details of the response vary across episodes. However, two key elements are typically present. First, at some point deposits are frozen, meaning that further withdrawals are strictly limited. In Argentina, deposits were frozen for a period of 90 days beginning on December 1, 2001; this freeze was extended in various ways until early 2003. Deposit freezes were also a regular feature in U.S. banking history, with the last occurring in March 1933 (Friedman and Schwartz [18]). Second, a rescheduling of payments occurs. Some demand deposits might be converted to time deposits with a penalty for early withdrawal. In addition, depositors may find that their access to funds is made contingent on their ability to demonstrate an urgent need to withdraw. The court system in Argentina, for example, was heavily involved in verifying individual depositors’ circumstances in 2001-2.

We focus on policy interventions that are efficient ex post, once a run is underway. Our objective is to capture the effects of institutional features that prevent policymakers from being able to precommit to follow a particular course of action in the event of a crisis. Instead, the authorities intervene during the crisis and attempt to improve the allocation of resources given the situation at hand. We show how the anticipation of such an intervention can generate the conditions necessary for a self-fulfilling run to occur. In other words, when depositors anticipate that a run will be followed by an (ex post efficient) intervention, this fact may give them an ex ante incentive to participate in the run. In this sense, such interventions can have a destabilizing effect on the banking system.

1 These figures include time deposits with penalties for early withdrawal. Demandable deposits (essentially checking and savings accounts) fell by more than $6 \%$ on that day. 
Deposit freezes (sometimes called suspensions of convertibility) have been studied before, but the focus has been almost exclusively on policies that are ex ante efficient. The classic paper of Diamond and Dybvig [10] presented a model with demand deposits in which a self-fulfilling bank run could occur, but then showed how an appropriate deposit freeze policy would remove all incentives for depositors to run. In their setting with no aggregate uncertainty, freezing deposits quickly enough in the event of a run guarantees that the banking system will be able to meet all of its future obligations. Given this guarantee, depositors without an urgent need for their funds have no incentive to withdraw and, therefore, a run will never start. Importantly, deposits are never frozen in equilibrium; the threat of a freeze is sufficient to convince depositors not to run. ${ }^{2}$

We show that the deposit freeze studied by Diamond and Dybvig [10] is typically not ex post efficient. In other words, if a run started and reached the point where deposits are to be frozen, a benevolent banking authority would not want to follow through with the freeze. The intuition is easy to see. Some of the depositors who have not yet withdrawn truly need access to their funds; freezing deposits imposes heavy costs on these individuals. In most cases, a better policy would be to delay the freeze or reschedule payments in a way that gives at least some funds to these depositors. Hence, a banking authority that is unable to pre-commit to follow the complete-freeze policy would not choose to do so once a run is underway.

We provide the first analysis of policy interventions that would be chosen ex post, once a run is underway, in the classic Diamond-Dybvig framework. We focus on the types of interventions observed in reality: deposit freezes and payment reschedulings with court intervention. We show that, compared to the policy of immediately freezing deposits, interventions that are desirable ex post are more lenient and allow more funds to be withdrawn. These withdrawals place additional strain on the banking system and decrease the assets available to meet future obligations. This fact, in turn, increases the incentive for a depositor to participate in the run. Taking the intervention that is ex post efficient as a benchmark, we show that self-fulfilling bank runs can arise in the canonical Diamond-Dybvig model. Our approach thus provides one possible answer to the question of “what’s missing?” in the Diamond-Dybvig model posed by Green and Lin [21].

Our results identify an important time-inconsistency problem in banking policy. Banking authorities would like depositors to believe they will be "tough" in response to a run. However, if a

$\overline{2}$ Gorton [20], Chari and Jagannathan [7], and Engineer [13] have also studied deposit freezes, but in each case the focus was again on the policy response that would be chosen ex ante, before a crisis were to start. 
run were to actually start, the authorities would not find it optimal to take a tough stand. Instead, they would choose a more lenient policy, and this policy can end up justifying the original decision of depositors to run. This type of time inconsistency was informally discussed by Kydland and Prescott [25, p. 477] in the context of government investment in flood control (see also the discussion in King [24]). As in the Kydland-Prescott example, we show that an inferior equilibrium exists if the government cannot pre-commit to a "tough" course of action.

Whether the wave of withdrawals by depositors during a banking crises reflects, at least in part, self-fulfilling behavior is an open question. System-wide banking crises are complex phenomena that typically occur in conjunction with a variety of unfavorable financial and macroeconomic factors, which makes answering this question difficult. Some important empirical work has been done recently (see, for example, Calomiris and Mason [4], [5]), but the evidence remains inconclusive (Ennis [14]). Demonstrating, as we do here, that this type of event is possible in a well-specified model - and identifying the circumstances that make it possible - is therefore a critical contribution to the overall debate.

Governments have also responded to the possibility of bank runs by establishing deposit insurance programs. While such programs have often proven effective in preventing runs, they have significant shortcomings. First, a credible deposit insurance program requires that the government be able to guarantee the real value of deposits in the event of a widespread run; this is not always feasible. Depositors in Argentina in 2001, for example, correctly anticipated that the government's resources were limited and that holders of insured deposits would suffer substantial real losses. Second, deposit insurance programs generate moral hazard. The costs of this distortion can be substantial, as shown during the Savings \& Loan crisis in the U.S. in the 1980s and 90s. Evaluating the benefits of deposit insurance requires understanding what happens in environments where it is not present and, in particular, whether other policy tools such as deposit freezes can effectively prevent system wide runs. $^{3}$

In recent decades, many of the functions traditionally associated with banking have been increasingly performed by non-bank institutions. Money-market funds and other arrangements perform maturity transformation by investing in long-term assets while offering investors the ability

3 In an environment similar to ours, Cooper and Ross [9] study the moral hazard costs of deposit insurance financed with taxation. They show that the government will choose to offer only partial deposit insurance in order to mitigate the moral hazard problem and that this partial insurance can be insufficient to rule out a self-fulfilling run. The run on the UK bank Northern Rock in September 2007 clearly highlights the limitations of partial deposit insurance schemes. 
to withdraw funds on demand. In any such arrangement, the issue of a run on the fund potentially arises: what happens if a large fraction of the investors attempt to withdraw at once? The reaction to a run on an investment fund is typically very similar to that for a bank run: redemptions are temporarily suspended and there is some rescheduling of payments. The recent turmoil in financial markets has witnessed several such cases. ${ }^{4}$ While our analysis is cast in terms of banks and depositors, it also sheds light on factors that may contribute to runs on these non-bank institutions. In particular, our analysis highlights the importance of thinking carefully about arrangements that will be desirable ex post in the event of a run and what incentives these arrangements give to participants ex ante.

The remainder of the paper is organized as follows. In Section 2 we present the basic model, including banking with demand deposit contracts and deposit freezes. In Section 3 we study the decision of when to freeze deposits in response to a bank run, while in Section 4 we examine interventions by the court system. In both cases, we derive conditions under which a self-fulfilling run cannot be ruled out when the policy is chosen ex post, once the run is underway. Finally, in Section 5 we offer some concluding remarks.

\section{The Basic Model}

Our basic framework is the now-standard model of Cooper and Ross [8], which generalizes the Diamond and Dybvig [10] environment by introducing costly liquidation and a non-trivial portfolio choice.

\subsection{The environment}

There are three time periods, indexed by $t=0,1,2$. There is a continuum of ex ante identical depositors with measure one. Each depositor has preferences given by

$$
v\left(c_{1}, c_{2} ; \theta\right)=u\left(c_{1}+\theta c_{2}\right),
$$

where the function $u$ is strictly increasing, strictly concave, and satisfies $u(0)=0$ and $u^{\prime}(0)=$ $\infty$. The variable $c_{t}$ represents consumption in period $t$ and $\theta$ is a binomial random variable with

4 One example is the Local Government Investment Pool of Florida, a money-market-style fund operated for state and local government agencies, which halted redemptions on November 29, 2007 after experiencing heavy withdrawals. Redemptions were also suspended by some other money-market and cash funds, as well as by a substantial number of hedge funds. 
support $\{0,1\}$. If the realized value of $\theta$ is zero, the depositor is impatient and only cares about consumption in period 1. A depositor's type (patient or impatient) is private information and is revealed to her at the beginning of period 1 . Let $\pi$ denote the probability with which each individual depositor will be impatient. By a law of large numbers, $\pi$ is also the fraction of depositors in the population who will be impatient. Note that $\pi$ is non-stochastic; there is no aggregate uncertainty in this model.

The economy is endowed with one unit of the consumption good per capita in period 0 . There are two constant-returns-to-scale technologies for transforming this endowment into consumption in the later periods. A unit of the good placed into storage in period 0 yields one unit of the good in either period 1 or period 2. A unit placed into investment in period 0 yields either $R>1$ in period 2 or $1-\tau$ in period 1 , where $\tau \in(0,1)$ represents a liquidation cost. In other words, investment offers a higher long-term return than storage but is relatively illiquid in the short term.

Depositors pool resources to form a bank, ${ }^{5}$ which allows them to insure against individual liquidity risk and minimize costly liquidation. There is also a benevolent banking authority (BA), which has the power to freeze deposits in period 1 if it deems that doing so would increase the welfare of depositors. In Section 4, we introduce a court system that can, once a deposit freeze has been declared, verify depositors’ types and reschedule payments.

The timing of events is as follows. We begin our analysis with all endowments deposited in the bank. ${ }^{6}$ In period 0 , the bank divides these resources between storage and investment. In period 1, depositors are isolated from each other and no trade can occur (as described in Wallace [29]). Depositors can, however, contact the bank and, hence, the bank is able to make payments to depositors from the pooled resources after types have been realized.

Upon learning her type, each depositor has the opportunity to either contact the bank in period 1 or wait and contact the bank in period 2. Those depositors who contact the bank in period 1 do so in a randomly-assigned order. We follow Wallace [29] in assuming that impatient depositors must consume immediately after contacting the bank in period 1. This sequential-service constraint implies that the payment made to such a depositor can only be contingent on the number of withdrawals that have occurred so far and not on the total number of withdrawals in the period, which

\footnotetext{
5 As is standard in the literature, this representative bank can be interpreted as the outcome of competition for deposits (with free entry) in period 0.

6 For simplicity, we do not explicitly examine the deposit decision of agents (the "pre-deposit game" of Peck and Shell [27]); our approach is the same as that in Diamond and Dybvig [10]. As will become clear later in the paper, our results can be extended to include the pre-deposit game in the usual way.
} 
has not yet been observed. The constraint captures an essential feature of banking: the banking system pays depositors as they arrive and cannot condition current payments to depositors on future information. We assume that the BA and the courts are also subject to the sequential-service constraint. Hence, for example, a deposit freeze can only apply to funds that have not yet been withdrawn; it cannot be made retroactive. ${ }^{7}$

\subsection{The first-best allocation}

Suppose a benevolent planner could observe each depositor's type and assign an allocation based on these types. This first-best allocation would clearly give consumption to impatient depositors only in period 1 and to patient depositors only in period 2. Let $c_{E}$ denote the amount given to impatient depositors (who consume "early") and $c_{L}$ the amount given to patient depositors (who consume "late"). Let $i$ denote the fraction of the total endowment placed into investment; the remaining $1-i$ would go into storage. Then the planner would choose $c_{E}, c_{L}$, and $i$ to solve

$$
\max \pi u\left(c_{E}\right)+(1-\pi) u\left(c_{L}\right)
$$

subject to

$$
\begin{aligned}
& \pi c_{E}=1-i, \quad(1-\pi) c_{L}=R i, \\
& c_{E} \geq 0, c_{L} \geq 0, \quad \text { and } \quad 0 \leq i \leq 1 .
\end{aligned}
$$

Let $\left(c_{E}^{*}, c_{L}^{*}\right)$ denote the solution to this problem, which is characterized by the condition

$$
u^{\prime}\left(c_{E}^{*}\right)=R u^{\prime}\left(c_{L}^{*}\right)
$$

Notice that $c_{L}^{*}>c_{E}^{*}$ necessarily holds, meaning that patient depositors consume more than impatient ones. Also note that this allocation satisfies the sequential service constraint. Because there is no aggregate uncertainty, the planner knows exactly how many impatient depositors will be encountered in period 1 and can condition all payments on this information.

In order for the possibility of a bank run to arise, the following condition must be satisfied.

Assumption 1. $c_{E}^{*}>1-\tau i^{*}$.

7 See Allen and Gale [1] for a study of financial/banking crises where the sequential service constraint is not imposed. They focus on crises that originate in a significant deterioration of economic fundamentals and discuss interventions that result in optimal risk sharing between early and late withdrawers. In their environment, crises are events that result in the optimal allocation of resources given the poor realization of fundamentals. 
This assumption implies that the amount of consumption given to an impatient depositor in the first-best allocation is greater than the per-capita liquidation value of all assets in period 1 ; in this sense, the planner's allocation provides liquidity insurance to depositors. Diamond and Dybvig [10] studied the model without liquidation costs and showed that $c_{E}^{*}>1$ holds when the coefficient of relative risk aversion is everywhere greater than unity. For such utility functions, Assumption 1 is clearly satisfied for any value of $\tau$. Cooper and Ross [8] showed how introducing the liquidation $\operatorname{cost} \tau$ to the model implies that liquidity insurance will be offered in the first-best allocation even for lower levels of risk aversion. This fact can be seen using the utility function

$$
u(c)=\frac{c^{1-\gamma}}{1-\gamma},
$$

where $\gamma>0$ is the coefficient of relative risk aversion. In this case, the first-best allocation is given by

$$
c_{E}^{*}=\frac{1}{\pi+(1-\pi) R^{(1-\gamma) / \gamma}} \quad \text { and } \quad c_{L}^{*}=\frac{R^{1 / \gamma}}{\pi+(1-\pi) R^{(1-\gamma) / \gamma}} .
$$

Using (1), Assumption 1 can be shown to be equivalent to the following condition on parameter values

$$
(1-\tau) R^{(1-\gamma) / \gamma}<1
$$

This expression shows that, even for values of $\gamma$ smaller than unity, Assumption 1 will hold whenever the liquidation $\operatorname{cost} \tau$ is large enough.

\subsection{Banking with demand deposits}

Diamond and Dybvig [10] showed how a bank offering demand-deposit contracts can generate the first-best allocation described above as an equilibrium outcome, even though depositors' types are private information. Suppose the bank allows each depositor to choose whether to withdraw her funds in period 1 or in period 2. It offers all depositors withdrawing in period 1 a pre-specified payment $c_{E}$ as long as the bank has funds; these payments are made to depositors as they arrive so that the arrangement respects the sequential service constraint. Depositors withdrawing in period 2 receive a pro-rata share of the matured assets. In effect, the demand-deposit contract generates a game in which each depositor observes her own type and then chooses in which period to contact the bank and withdraw. After these decisions have been made, withdrawing depositors begin to contact the bank in a randomly-assigned order. 
If the bank invests a fraction $i^{*}$ of its assets and sets the early payment equal to $c_{E}^{*}$, then there is an equilibrium of this game in which the first-best allocation obtains. Impatient depositors will always choose to withdraw in period 1 . A patient depositor who expects all other patient depositors to wait until period 2 to withdraw anticipates receiving $c_{E}^{*}$ if she withdraws early and $c_{L}^{*}$ if she waits. Since $c_{L}^{*}>c_{E}^{*}$ holds, her best response is to wait and this strategy profile is an equilibrium. However, as Diamond and Dybvig [10] pointed out, this simple deposit contract also generates an equilibrium that resembles a run on the banking system. Suppose an individual patient depositor expects all others - both impatient and patient - to withdraw in period 1. Under Assumption 1 she knows the bank will not be able to satisfy all of these withdrawal requests. Depositors who contact the bank early enough will receive $c_{E}^{*}$, but a depositor who arrives late in period 1 or waits until period 2 will receive nothing. Her best response in this situation is to also attempt to withdraw in period 1 and, thus, there is an equilibrium in which all depositors try to withdraw at once.

We say that the banking system is fragile if this type of run equilibrium exists when the period-1 payment on demand deposits is set at $c_{E}^{*}$. Our interest is in whether or not - and under what conditions - deposit freeze policies can eliminate this fragility and ensure that the first-best allocation of resources is achieved.

\subsection{Bank runs and deposit freezes}

After pointing out the fragility of the simple demand-deposit contract, Diamond and Dybvig [10] showed how a particular deposit freeze policy could make the first-best allocation the unique equilibrium outcome. In practice, a deposit freeze is the most common policy response to a banking panic. As mentioned above, such freezes (often called "banking holidays") were a regular occurrence in the U.S. prior to 1933. More recently, Brazil (1990), Ecuador (1999), and Argentina (2001) have declared widespread deposit freezes to stop the outflow of deposits from the banking system (see IMF [22]).

In the model, during "normal times" a fraction $\pi$ of depositors withdraw in period 1 . As the first $\pi$ withdrawals are taking place, therefore, the BA is unable to discern whether or not a run is underway. Once the fraction of depositors withdrawing in period 1 exceeds $\pi$, however, the BA realizes that a run must be underway and reacts to this information. Suppose it is known that the BA will completely freeze deposits, directing the bank to suspend further payments until period 2, whenever more than $\pi$ depositors attempt to withdraw in period 1. Diamond and Dybvig [10] 
showed that this policy rules out the bank run equilibrium.

Proposition 1 (Diamond and Dybvig [10]) If deposits are frozen after $\pi$ withdrawals in period 1, the banking system is not fragile.

The intuition behind this result is simple. If a patient depositor believes the BA will freeze deposits after $\pi$ withdrawals in period 1, then she is sure the bank will have enough resources to pay at least $c_{L}^{*}$ in period 2. Since $c_{L}^{*}>c_{E}^{*}$ holds, waiting to withdraw is a strictly dominant strategy for her, and the only equilibrium has all patient depositors withdrawing in period 2. Note that deposits will never actually be frozen in equilibrium, because a run never takes place. In this way, the BA can costlessly eliminate the possibility of a bank run by means of a temporary deposit freeze.

\subsection{Discussion}

The deposit freezes observed in reality typically differ in at least two important ways from the one studied by Diamond and Dybvig [10] and described in Proposition 1. First, the freeze is usually declared relatively late in the course of the overall crisis. Figure 1 presents the evolution of total bank deposits in Argentina during the crisis of 2001-2. From their peak on February 28, 2001, total deposits had fallen $21.8 \%$ by the time the freeze was declared on December $1,2001 .^{8}$ In the model, if the deposit freeze is delayed and more than $\pi$ withdrawals take place in period 1 , the payments the bank is able to make in period 2 will decrease. If the freeze is delayed long enough, patient depositors might prefer to participate in the run and the result in Proposition 1 could be overturned.

Second, deposits are often not frozen completely; some types of withdrawals may still be allowed. In Argentina, for example, during the freeze announced on December 1, 2001, depositors were allowed to withdraw up to 1,000 pesos per month from each account. A similar policy was used in Brazil during the freeze implemented in March 1990. In addition, the court system in Argentina ordered banks to make payments to a large number of depositors after the freeze was in

\footnotetext{
8 The large upward jump in January 2002 corresponds to the abandonment of the currency board and devaluation of the peso. Dollar-denominated deposits, which were approximately $70 \%$ of the total, were converted into pesos at the official exchange rate of 1.4 pesos/dollar. This conversion increased total deposits, measured in pesos, by approximately $28 \%$, as depicted in the figure. It is also interesting to note that several run-like events in the summer of 2001 and again in October 2001 did not lead to deposit freezes. In each of these cases, the authorities were able to halt the decline in deposits through various announcements aimed at restoring confidence, such as fiscal adjustment measures and an increase in IMF standy-by credit. See Dominguez and Tesar [12] for details.
} 
place. Figure 1 shows how total deposits in the banking system in Argentina continued to fall dramatically after the freeze was declared. In the model, such additional payments from the banking system also tend to undermine the incentives for patient depositors to wait and have the potential to overturn the result in Proposition $1 .^{9}$

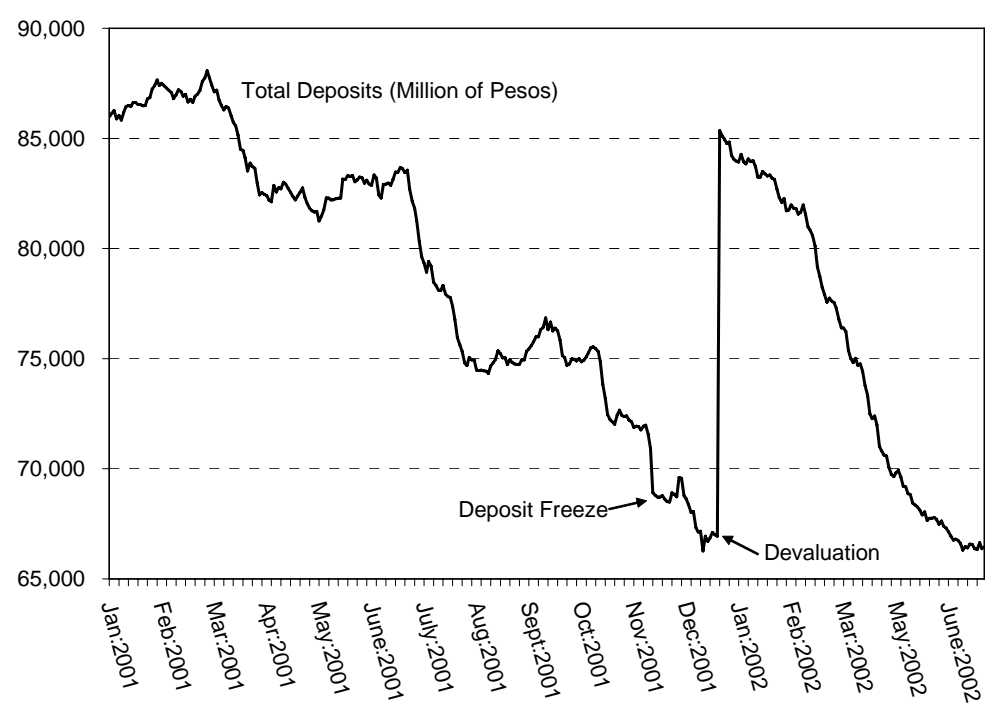

Figure 1: Evolution of Deposits During the Crisis in Argentina 2001-2

Source: Ministry of the Economy and Production of Argentina.

In the remainder of the paper, we investigate why the authorities might choose to allow additional withdrawals when a run is underway, even though these withdrawals place further strain on the banking system. In light of Proposition 1, the BA would clearly like to pre-commit to freezing deposits after $\pi$ early withdrawals. Experience from crises such as the one in Argentina indicates that institutional factors may limit the ability of the banking authorities to pre-commit to future actions. For this reason, we proceed by assuming that the BA chooses the intervention as the crisis develops. To isolate the implications of lack of commitment from other government-induced distortions, we assume the BA reacts optimally, given that a crisis is underway. Even under this

9 These same features often characterize the response to a run on non-bank financial institutions as well. The Local Government Investment Pool of Florida, for example, suspended redemptions in November 2007 after more than $46 \%$ of all account balances in the fund had been withdrawn (including $27 \%$ in two days). The fund reopened one week later, with $14 \%$ of the balances remaining frozen and a system of redemption limits/fees applying to the other $86 \%$. (See Local Government Investment Pool Newsletter 2007Q4, Florida State Board of Administration, January 22, 2008). 
relatively optimistic premise, we will show that ex post intervention may create fragility in the banking system.

\section{Choosing When to Freeze}

In this section, we investigate the problem that a benevolent banking authority faces in deciding when to declare a deposit freeze and how this ex post decision, in turn, affects the ex ante incentives of depositors to participate in a run. Consider a situation where the bank has already paid out $c_{E}^{*}$ to a fraction $\pi$ of depositors. If additional depositors attempt to withdraw in period 1 , the BA recognizes that a run must be underway. It then realizes that some of the funds already paid out were given to depositors who are actually patient and that some impatient depositors have not yet been served. Freezing deposits immediately implies giving nothing to the remaining impatient depositors, which may be very costly from a social point of view.

\subsection{Ex post efficient deposit freezes}

When would a benevolent banking authority choose to freeze deposits? Let $\pi_{s}$ denote the "freeze point," that is, the fraction of depositors the BA would choose to serve before freezing deposits when faced with a run. Then the BA would seek to maximize depositor welfare by solving the following problem

$$
\max _{\left\{\pi_{s}\right\}} W\left(\pi_{s}\right) \equiv \pi_{s} u\left(c_{E}^{*}\right)+\left(1-\pi_{s}\right)(1-\pi) u\left[c_{L}\left(\pi_{s}\right)\right]
$$

subject to

$$
\begin{gathered}
c_{L}\left(\pi_{s}\right)=\frac{\frac{R}{1-\tau}\left(1-\tau i^{*}-\pi_{s} c_{E}^{*}\right)}{(1-\pi)\left(1-\pi_{s}\right)} \quad \text { and } \\
\pi \leq \pi_{s} \leq \pi_{s}^{U},
\end{gathered}
$$

where $\pi_{s}^{U}$ is the maximum proportion of depositors that can be paid $c_{E}^{*}$ in period 1 , that is, $\pi_{s}^{U}=$ $\left(1-\tau i^{*}\right) / c_{E}^{*}$. Note that (1) and Assumption 1 together imply $\pi<\pi_{s}^{U}<1$.

The objective (4) states that a fraction $\pi_{s}$ of depositors will be served in period 1 and each will receive $c_{E}^{*}$. Of the remaining $1-\pi_{s}$ depositors, only a fraction $1-\pi$ will be patient and return in period 2. The other $\pi$ will be impatient and will receive nothing, leaving them with a utility level of zero. The function $c_{L}\left(\pi_{s}\right)$ in (5) represents the consumption of patient depositors who are 
forced by the freeze to return in period 2; the numerator equals the total resources of the bank in period 2 while the denominator is the mass of patient depositors who were not served in period 1. The second constraint reflects both sequential service and feasibility: the BA only discovers that a run is underway after $\pi$ withdrawals have been made, and it runs out of funds after serving $\pi_{s}^{U}$ depositors.

Under Assumption 1, the function $c_{L}\left(\pi_{s}\right)$ is strictly concave as depicted in Figure 2. Combined with the concavity of the utility function, this fact implies that (4) has a unique solution, which we denote $\pi_{s}^{M}$. In choosing when to freeze, the BA faces a tradeoff. On one hand, delaying the freeze allows some additional impatient depositors to consume in period 1 , giving them a utility level of $u\left(c_{E}^{*}\right)$ instead of zero. On the other hand, the delay decreases the payment available for the patient depositors who are served in period 2, as shown in (5). In addition, a fraction $(1-\pi)$ of the additional early payments end up going to patient depositors participating in the run; these depositors would be more efficiently served in period 2. The ex post efficient freeze point $\pi_{s}^{M}$ optimally balances these considerations. ${ }^{10}$

In making their withdrawal decisions, depositors recognize that the BA will react to a run by freezing deposits only after $\pi_{s}^{M}$ withdrawals have been made. Our interest is in whether or not the banking system is fragile when depositors anticipate this policy response.

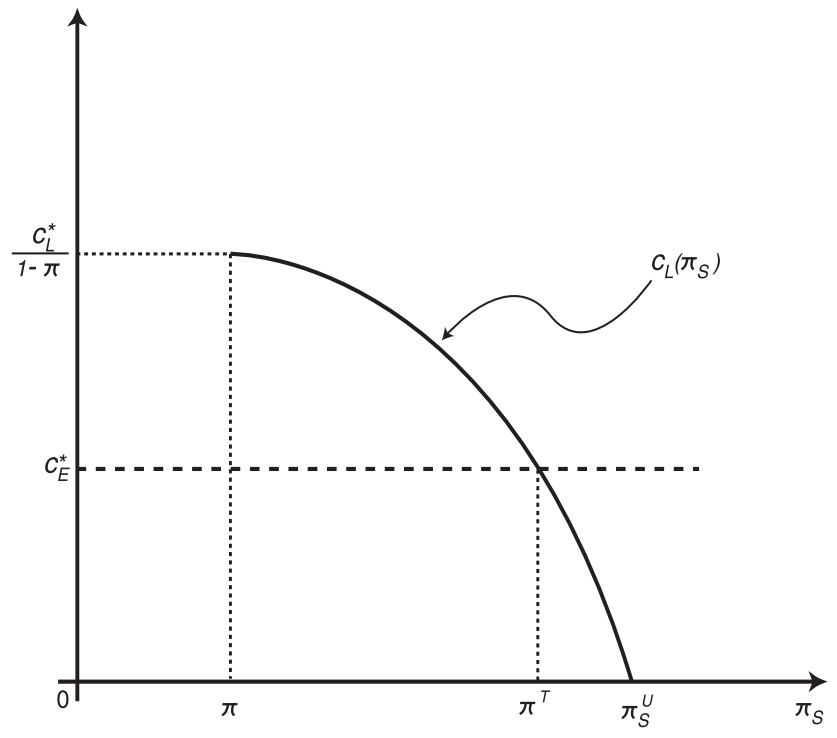

Figure 2: Period 2 payoff after a deposit freeze at $\pi_{s}$

10 Note that $\pi_{s}^{M}$ remains the desired suspension point even after some additional withdrawals, beyond $\pi$, have been allowed. These extra withdrawals are fully anticipated in the formulation of (4) and, hence, their occurrence does not change the optimal freeze point. 


\subsection{Equilibrium under the efficient policy}

The efficient freeze point $\pi_{s}^{M}$ may be equal to $\pi$, in which case Proposition 1 applies and the banking system will not be fragile. In fact, the BA does not need to freeze deposits right at $\pi$ in order for this result to obtain; it is sufficient for the BA to suspend at any point where it can still afford to give more than $c_{E}^{*}$ to depositors who are paid in period 2. Since the function $c_{L}\left(\pi_{s}\right)$ is strictly decreasing, there is an interval of such values, as depicted in Figure 2.

Lemma 1 There exists a value $\pi^{T}>\pi$ such that for all freeze points $\pi_{s} \in\left[\pi, \pi^{T}\right)$, the banking system is not fragile.

This lemma shows that the effectiveness of a deposit freeze policy in preventing a self-fulfilling

run depends crucially on whether the ex post efficient freeze point $\pi_{s}^{M}$ is smaller or larger than the threshold value $\pi^{T}$. If it is smaller, depositors anticipate that the BA will impose the freeze relatively quickly and, since $c_{L}\left(\pi_{s}^{M}\right)>c_{E}^{*}$ holds, a patient depositor is better off waiting than participating in the run. In this case, a run will never start and deposits will never need to be frozen. If $\pi_{s}^{M}$ is greater than $\pi^{T}$, however, depositors expect the BA to impose a deposit freeze relatively late and those who sit out the run will receive less than $c_{E}^{*}$. A patient depositor who expects others to run will, therefore, choose to run as well and a self-fulfilling bank run can arise.

The next proposition is the main result of this section. It shows that, in some situations, the efficient deposit freeze occurs after the threshold $\pi^{T}$. A proof of the proposition is given in the Appendix.

Proposition 2 Under the (ex post) efficient deposit freeze, the banking system is fragile if and only if

$$
\pi-\frac{u^{\prime}\left(c_{E}^{*}\right) c_{E}^{*}}{u\left(c_{E}^{*}\right)}\left[\frac{R}{1-\tau}-(1-\pi)\right] \geq 0 .
$$

For the constant relative risk aversion utility function in (2) with $\gamma \in(0,1)$, this condition reduces to

$$
\pi \geq \frac{1-\gamma}{\gamma}\left(\frac{R}{1-\tau}-1\right) .
$$

Condition (7) shows that the banking system will tend to not be fragile if $\pi$ is small. When few depositors have a real need to consume early, the cost of temporarily freezing deposits and leaving 
these depositors with nothing is relatively small. In addition, a large proportion of any additional payments made in period 1 during the run would go to depositors who are actually patient. The optimal response to a run in this case is to freeze deposits relatively quickly and preserve a high payment for the large number of patient depositors expected to come back and withdraw in period $2 .^{11}$

Notice that condition (7) will necessarily be violated if the right-hand side of the inequality is greater than one, or if we have

$$
\gamma<1-\frac{1-\tau}{R}
$$

In this case, the efficient deposit freeze occurs early enough to rule out a self-fulfilling run for any value of $\pi$. Depositors must exhibit a minimal amount of risk aversion for bank runs to be an issue in this framework. On the other hand, notice that for any given values of $\pi, R$, and $\tau$, condition (7) will hold if $\gamma$ is close enough to unity. In other words, fixing all other parameter values, the efficient deposit freeze occurs too late to rule out a self-fulfilling run equilibrium if depositors are sufficiently risk averse.

For values of $\gamma$ greater than unity, a slight change in the utility function is required because (2) no longer satisfies $u(0)=0$. To include this case in the analysis, we can modify the functional form to

$$
u(c)=\frac{(c+b)^{1-\gamma}-b^{1-\gamma}}{1-\gamma}
$$

where $b$ is a small, positive constant. Notice that this function satisfies $u(0)=0$ for all values of $\gamma>0$ and $b>0$. The coefficient of relative risk aversion is no longer constant, but it converges to $\gamma$ as $b$ goes to zero for all levels of $c$. It can be shown that for any $\gamma>1$, the condition for fragility (6) is satisfied under this utility function as long as $b$ is small enough. In other words, when $\gamma>1$ (and $b \approx 0$ ), the banking system is fragile for any value of $\pi$. Combined with the discussion above, this result gives us the following corollary.

Corollary 1 Under (2) or (9) and the ex post efficient deposit freeze, the banking system is fragile if depositors are sufficiently risk averse.

\footnotetext{
11 It is worth noting that if $\pi$ is small enough, $W^{\prime}(\pi) \leq 0$ will hold and the ex post efficient policy will set $\pi_{s}^{M}=\pi$. In this case, and only in this case, the BA would choose to follow the policy proposed by Diamond and Dybvig [10] of freezing deposits immediately after identifying a run.
} 


\subsection{Discussion}

The results above give conditions under which the banking system is fragile and conditions under which it is not. When it is not fragile (that is, when the equilibrium is unique), this is clearly the end of the story - no bank run will occur and the first-best allocation will obtain. What happens in the fragile case, where the equilibrium is not unique? Would a bank run and the subsequent deposit freeze actually occur? These questions raise the difficult issue of equilibrium selection, a formal analysis of which is beyond the scope of the present paper. However, it is relatively easy to see how the standard approach in the existing literature can be applied to our model and why our results above capture the essential elements at play.

The most common approach to equilibrium selection in this type of model is to assume that depositors condition their actions on the realization of an extrinsic "sunspot" variable; the run equilibrium is played if spots appear on the sun, otherwise the no-run equilibrium is played. The probability of a run is then equal to the (exogenous) probability of sunspots. The payment offered by the bank in period 1 may depend on this probability but not on the realization of the sunspot variable, because the latter is not observed by the banking authorities. This approach was suggested in Diamond and Dybvig [10, p. 410] and explicitly taken in Cooper and Ross [8], Peck and Shell [27], and others.

Whether or not a run occurs in equilibrium under this approach depends on both the ex ante probability of sunspots and the realization of this variable. If the probability is high, for example, banks may choose to offer a payment much smaller than $c_{E}^{*}$ in order to convince depositors not to run. Cooper and Ross [8] labelled such a deposit contract "run proof." Under a run-proof contract, depositors receive low levels of liquidity insurance and, hence, have substantially lower expected utility than in the first-best allocation. For this reason, choosing a run-proof deposit contract will not be optimal if the probability of a run is small enough. ${ }^{12}$

Two main conclusions emerge from this type of analysis. First, whenever the banking system is fragile, an equilibrium can be constructed in which a run occurs with positive probability and all contracting and deposit decisions take this probability into account (see Peck and Shell [27]). In our setting, this equilibrium will include a deposit freeze in states where a run occurs. Note that

12 In Ennis and Keister [17], we explicitly formulate these arguments in a model where all participants take into account the ex ante probability of a run as well as the authorities' inability to pre-commit to a course of action. Also see Ennis and Keister [15] for a general discussion of policy choices and equilibrium selection in environments similar to the one studied here. 
this result contrasts sharply with Diamond and Dybvig [10], where the threat of a deposit freeze eliminates the possibility of a run. Second, the ex ante possibility of a run will lead banks to choose a period-1 payment different from $c_{E}^{*}$, so that the first-best allocation does not obtain even in states where a run/freeze does not occur (see especially Cooper and Ross [8] and Ennis and Keister [16]).

An alternative approach would be to attempt to resolve the multiplicity of equilibrium using the global-games techniques developed by Carlsson and van Damme [6] and others. Goldstein and Pauzner [19] show how the Diamond-Dybvig model can be modified for this purpose. However, as is clear from their analysis, using the global-games approach in this setting requires additional assumptions and restrictions on contracts beyond those implied by the physical environment. ${ }^{13}$ Furthermore, the ex post interventions in our framework will likely have important effects on the structure of beliefs and, hence, may tend to undermine the uniqueness of equilibrium (see, for example, Angeletos and Werning [2]). Nevertheless, we conjecture that such an exercise, if successful, would lead to the same conclusion as the sunspots-based approach described above: under the conditions we identify in this paper, the possibility of self-fulfilling bank runs will distort the allocation of resources away from the first-best.

The bottom line, therefore, is that whenever the banking system is fragile, the possibility of self-fulfilling runs will create costly distortions in the economy. Our results above characterize the conditions under which this happens if the authorities choose when to freeze deposits in order to maximize (ex post) depositor welfare. In the next section we examine what happens when intervention not only involves a deposit freeze but also some degree of payment rescheduling enforced by a court system that can verify depositors' types.

\section{Rescheduling Payments}

After a run is identified, it would be socially optimal to combine the deposit freeze with some degree of payment rescheduling. Ideally, the banking authorities would like to sort depositors by type and allow only those who are truly impatient to withdraw in period 1 . In addition, it would be optimal to reduce, if possible, the payment given to these depositors below $c_{E}^{*}$ in order to economize on costly asset liquidation. In this section, we study the ex post efficient way of

\footnotetext{
13 In Goldstein and Pauzner [19], pre-commitment is implicitly assumed and the set of possible contracts is exogenously restricted to generate the potential for multiplicity. In our environment, in contrast, multiplicity arises naturally as a result of ex post efficient intervention.
} 
rescheduling payments and the ex ante incentives that this policy reaction gives to depositors. We derive conditions under which depositors who expect a run to be followed by a deposit freeze with payment rescheduling would choose to participate in the run, implying that the banking system is fragile.

There are a variety of ways in which payments from the banking system can be rescheduled. Demand deposits can be converted into time deposits with a penalty for early withdrawal, leaving agents who withdraw with less than the face value of their deposits. When deposit contracts are denominated in local currency, policies that generate inflation will decrease the real value of the payments received by depositors. Deposit contracts denominated in foreign currency can be converted into local currency at an unfavorable exchange rate, again reducing the real value of depositors' claims. In practice, all of these methods were used to some degree following the deposit freeze in Argentina in 2001.

Another prominent feature of the crisis in Argentina was the involvement of the court system. Following the deposit freeze in December 2001, depositors claiming to have urgent financial needs (due to, for example, illness or hospitalization) could file a legal recourse requesting withdrawal of some or all of their funds from the banking system while the freeze was in place. Nearly 200,000 such cases were filed between December 2001 and June 2003, and the courts awarded payments to depositors totaling over 14 billion pesos. Of the value of total deposits in the system as of March 2002 more than $21 \%$ were later paid out to depositors via legal recourse. This process of legal mediation was based, in part, on the presumption that the courts had some ability to differentiate between depositors who needed funds urgently and those who did not.

Court intervention provides a particularly convenient way to study the effects of rescheduling payments in the context of our model. If we assume the courts can both determine a depositor's true type and reschedule payments without constraint, they will be able to directly implement the efficient continuation allocation after the freeze. This approach allows us to focus on the ex ante incentives generated by the intervention with minimal complications. In our analysis below, we first derive the results in terms of court intervention. We then discuss how other, less direct methods of rescheduling payments would lead to similar results.

\subsection{Court intervention}

Suppose that once the BA declares a deposit freeze, the court system intervenes and verifies the true 
type of each remaining depositor. In principle, one would expect verifying types to involve some administrative costs. To keep the analysis as simple as possible, we abstract from such costs: we assume that type verification occurs costlessly, but only after $\pi$ depositors have already withdrawn and the BA has declared a deposit freeze. ${ }^{14}$ This assumption prevents the system from using the courts to completely overcome the private information problem. With a positive verification cost, it would be optimal not to screen the types of the first $\pi$ individuals to withdraw if the likelihood of facing a run is relatively small. On the other hand, if the cost is not too high, using the verification technology will be desirable ex post, after the deposit freeze has been declared.

As before, the bank pays $c_{E}^{*}$ to the first $\pi$ depositors who withdraw in period 1 . If more than $\pi$ depositors attempt to withdraw in period 1, the BA realizes that a run is underway. Given the ability of the courts to verify types, the BA will clearly choose to declare an immediate deposit freeze. Once the freeze is in place, the courts intervene, verify which of the remaining depositors are truly impatient, and decide how much to pay each of them in period 1 . This payment is chosen to solve the following problem:

$$
\max _{c_{E}, c_{L}, i}(1-\pi)\left[\pi u\left(c_{E}\right)+(1-\pi) u\left(c_{L}\right)\right]
$$

subject to

$$
\begin{gathered}
(1-\pi) \pi c_{E} \leq(1-\tau) i^{*} \\
(1-\pi)^{2} c_{L}=R\left[i^{*}-\frac{(1-\pi) \pi c_{E}}{(1-\tau)}\right] \\
c_{E} \geq 0 \text { and } c_{L} \geq 0
\end{gathered}
$$

Note that the solution to this problem is the first-best continuation allocation, that is, the most efficient allocation of resources conditional on $\pi$ agents already having each received $c_{E}^{*}$ from the banking system. Of the $1-\pi$ remaining depositors, a fraction $\pi$ are impatient and will be served in period 1 , while a fraction $1-\pi$ are patient and will not be served until period 2 . The first constraint in the problem reflects the fact that all of the resources in storage have already been paid out to the first $\pi$ depositors who withdrew; additional period-1 payments can only come from liquidating investment. The second constraint is the standard pro-rata share of remaining resources

14 Gorton [20] offers a related interpretation of the role of a deposit freeze. In his model, a deposit freeze is assumed to trigger a (costly) verification of the value of the bank's assets, which is random and imperfectly observed by depositors. He shows that, in some cases, the freeze can actually be Pareto improving because it prevents the unwarranted liquidation of assets in good states of nature. 
that determines the payment in period 2. Let $\left(c_{E R}^{*}, c_{L R}^{*}\right)$ denote the solution to this problem, which is characterized by the condition

$$
u^{\prime}\left(c_{E R}^{*}\right)=\frac{R}{1-\tau} u^{\prime}\left(c_{L R}^{*}\right)
$$

Note that $c_{L R}^{*}>c_{E R}^{*}$ holds.

At the beginning of period 1 , depositors anticipate that the BA will respond to a run by declaring a freeze, triggering a court intervention and resulting in the continuation payments $\left(c_{E R}^{*}, c_{L R}^{*}\right)$. Given these payments, would a patient depositor choose to run at the beginning of period 1 if she believes that all other depositors will? She will have an expected payoff of

$$
\pi u\left(c_{E}^{*}\right)+(1-\pi) u\left(c_{L R}^{*}\right)
$$

if she also runs, but will receive $c_{L R}^{*}$ for certain if she waits. Running is a best response for her if and only if the payment offered before the deposit freeze, $c_{E}^{*}$, is at least as large as the payment she receives if she waits, $c_{L R}^{*}$. We can, therefore, characterize the situations in which the banking system is fragile as follows.

Proposition 3 Under a deposit freeze followed by court intervention, the banking system is fragile if and only if $c_{E}^{*} \geq c_{L R}^{*}$.

To understand precisely when this situation will arise, it is helpful to again use the constant relative risk aversion utility function in (2). In this case, we can explicitly solve for the rescheduled payments

$$
\begin{aligned}
c_{E R}^{*} & =\frac{1}{\pi+(1-\pi)[R /(1-\tau)]^{(1-\gamma) / \gamma}} \frac{(1-\tau) i^{*}}{(1-\pi)} \text { and } \\
c_{L R}^{*} & =\frac{[R /(1-\tau)]^{1 / \gamma}}{\pi+(1-\pi)[R /(1-\tau)]^{(1-\gamma) / \gamma}} \frac{(1-\tau) i^{*}}{(1-\pi)} .
\end{aligned}
$$

Straightforward algebra then shows that the condition $c_{E}^{*} \geq c_{L R}^{*}$ is equivalent to the following:

$$
R^{\frac{1}{\gamma}} \frac{\left(\frac{R}{1-\tau}\right)^{\frac{1-\gamma}{\gamma}}}{\pi+(1-\pi)\left(\frac{R}{1-\tau}\right)^{\frac{1-\gamma}{\gamma}}} \leq 1
$$


Corollary 2 Under (2) and a deposit freeze followed by court intervention, the banking system is fragile if and only if (11) holds.

Notice that (11) will necessarily be violated if $\pi$ is close to zero, which is reminiscent of condition (7) in the previous section. When there are relatively few impatient depositors, the additional early payments ordered by the courts amount to a relatively moderate sum and, hence, there will be sufficient assets left to offer a relatively high payment to depositors in period 2 . Also notice that condition (11) cannot hold if $\gamma<1$. In fact, using (3) and (10) it is straightforward to show that $\gamma<1$ implies $c_{L R}^{*}>c_{L}^{*}>c_{E}^{*}$. In this case, waiting until period 2 is clearly a dominant strategy for patient depositors. ${ }^{15}$

Things are different when $\gamma>1$. In this case, given all other parameter values, condition (11) will necessarily hold for high enough values of the liquidation cost $\tau$. In other words, if the coefficient of relative risk aversion is greater than unity, whenever liquidation costs are large the banking system will be fragile. ${ }^{16}$

Corollary 3 Under (2) and a deposit freeze followed by court intervention, for any $\gamma>1$, there exists $\bar{\tau}<1$ such that $\tau \geq \bar{\tau}$ implies that the banking system is fragile.

Villamil [28] suggests that a way to commit to a full suspension of payments is by making investments that cannot, under any circumstances, be liquidated (and shows how the optimal lending contract can have this property in some settings). This idea can be captured in our notation by setting $\tau=1$, in which case suspending payments after all liquid assets have been depleted is clearly ex post efficient. However, Corollary 3 points out the knife-edge nature of this argument. If liquidation is costly but not impossible (i.e., $\tau$ is close to, but not equal to, unity), the courts will still mandate the liquidation of some investment after a deposit freeze and this action will make the banking system fragile.

Given a value of the liquidation cost (and all other parameter values), condition (11) will also hold if $\gamma$ is large enough. The result in Corollary 2 can, therefore, be stated another way: the

\footnotetext{
15 In addition, when $\gamma<1$ the payments $\left(c_{E R}^{*}, c_{L R}^{*}\right)$ represent a run-proof contract (Cooper and Ross [8]) and, hence, there are sufficient resources to assign $c_{E R}^{*}$ to all remaining depositors in period 1 . This fact implies that even if the courts did not verify types after the intervention, only depositors who are truly impatient would appeal to the courts to withdraw. In a sense, verifying types is redundant in this case.

16 Note that, in this section, there are no circumstances in which depositors receive zero consumption and, therefore, we can study the case where the coefficient of relative risk aversion is greater than one without changing the form of the utility function to (9).
} 
banking system is fragile if depositors are sufficiently risk averse.

Corollary 4 Under (2) and a deposit freeze followed by court intervention, given all other parameter values, there exists $\bar{\gamma}>1$ such that $\gamma \geq \bar{\gamma}$ implies the banking system is fragile.

In some situations, institutional constraints may limit the authorities' ability to decrease the payment given to impatient depositors. For example, the court system in Argentina often awarded depositors the right to withdraw the entire face value of their deposits. Even after the peso was devalued, some depositors were awarded the value of their deposits in dollars at the pre-devaluation exchange rate; this amounts to giving depositors $c_{E}^{*}$ in our model. It is fairly easy to see that such institutional constraints make fragility more likely to obtain in our model. Suppose that, once deposits are frozen, the authorities can effectively sort depositors by type, but are not able to decrease the early payment all the way to $c_{E R}^{*}$. Suppose instead that the remaining impatient depositors are each given $\widehat{c}_{E R}$, with $c_{E}^{*} \geq \widehat{c}_{E R}>c_{E R}^{*}$. Then feasibility implies that $\widehat{c}_{L R}$ must be smaller than $c_{L R}^{*}$ and it follows from Proposition 3 that the condition for fragility is strictly weaker than (11). In other words, institutional constraints that make it difficult to reschedule payments do not mitigate the problem of fragility; instead, they make fragility more likely to obtain.

\subsection{Discussion}

The key to understanding the limits of intervention is to realize that by the time the run is discovered, some resources have already been given to the first $\pi$ depositors. The sequential service constraint implies that these resources cannot be reclaimed by the BA and, hence, the losses associated with the run will be borne by the remaining $(1-\pi)$ depositors. In the model, reclaiming these resources is not possible because depositors consume the goods as soon as they withdraw. ${ }^{17}$ More generally, however, the constraint captures the idea that depositors can convert their funds into assets that are difficult for the authorities to reclaim and/or tax.

Suppose, for example, that deposit contracts were fixed in nominal terms (as in Diamond and Rajan [11]) and individuals expected the government to finance additional withdrawals by printing currency, so that a run would be followed by inflation and/or a devaluation of the currency. Then

17 Diamond and Dybvig [10, p. 410] discuss a deposit insurance system that is financed by taxing depositors after they have withdrawn. Wallace [29] pointed out that such a system is inconsistent with a specification of the physical environment that explicitly includes the sequential service constraint. 
depositors would rush to change their funds into another currency as soon as they withdraw. ${ }^{18}$ The cost of the inflation/devaluation would, therefore, fall largely on those depositors who withdraw after the policy response has taken place. This is just an example of Wallace's [29] general point: in a wide variety settings, the sequential service constraint will apply to the real allocation of resources. Policy responses are largely ineffective at changing the consumption of the first $\pi$ depositors to withdraw. Instead, they serve primarily to reschedule the payments of the remaining $(1-\pi)$ depositors. Given this limitation, the authorities will attempt to use whatever tools they have available to implement the efficient continuation allocation $\left(c_{E R}^{*}, c_{L R}^{*}\right)$.

Another important element of our analysis is the fact that a run on the banking system generates an aggregate shortage of liquid assets. If a run were to occur at only one or a few banks, these banks might be able to avoid freezing deposits or liquidating assets by borrowing in the interbank market. When the run is system-wide, however, methods for reallocating liquidity are largely ineffective because they do nothing to ameliorate the aggregate shortage.

Central banks can, in some instances, ease an aggregate liquidity shortage by using a discount window or related tools to exchange liquid assets for the illiquid assets held by banks. For example, the central bank could hold a reserve of liquid assets and stand ready to lend from this reserve in times of crisis. It is straightforward to modify the constraints in the banking problem (1) to allow the BA to maintain a buffer of liquid assets that will not be paid out in period 1 under normal circumstances, but which would be used in the event of a run. If the buffer is large enough, the banking system as a whole - including this buffer - would no longer be illiquid and the run equilibrium would cease to exist.

Notice, however, that maintaining such a buffer has a real cost: it prevents the economy from achieving the first-best allocation in the event that a run does not occur. As a result, one can show that as long as the probability of a run is small, holding a large enough buffer to rule out the run equilibrium is not optimal. ${ }^{19}$ In other words, in the environment studied here, it is ex ante efficient for the banking system as a whole - including any central bank buffer - to be illiquid. Hence, a system-wide run will necessarily generate an aggregate liquidity shortage, leading to liquidation of investment and/or some type of payment rescheduling.

\footnotetext{
18 This rush to change currencies could help explain why a major banking crisis is often accompanied by a currency crisis. For a discussion of the evidence on "twin crises," see Kaminsky and Reinhart [23].

19 In Ennis and Keister [16], we studied a model in which it was simply assumed that the BA could not freeze deposits and showed that it is never optimal to hold any buffer of liquid assets.
} 


\section{Concluding Remarks}

The behavior of individuals during a banking crisis depends crucially on how they expect the authorities to respond to events. If it were known that the authorities would respond to a run by immediately freezing all remaining deposits then, in a wide range of model environments, selffulfilling runs would not happen. However, this type of response is likely to be highly inefficient ex post, in the event that a run actually occurs. In environments where the authorities cannot precommit to a "tough" policy response, taking these ex post concerns into account can dramatically change the analysis. We illustrated this fact by deriving ex post efficient policy responses to a run in the classic framework of Diamond and Dybvig [10] and showing how these interventions can generate an ex ante incentive for depositors to participate in the run. Our results demonstrate how policy interventions, even ones that are highly desirable ex post, can have a destabilizing effect on the banking system.

Banking crises are often associated with periods of significant political turmoil and weak institutions, which makes any sort of commitment by government agencies difficult to achieve. Such was certainly the case in Argentina, with the President of the country resigning less than three weeks after the deposit freeze was declared in December 2001 and his successor resigning after only a week in office. Political instability was also present in the U.S. during the banking crisis of 1932-33, when a change in administration made commitment to a coherent policy very difficult (see Friedman and Schwartz [18] pp. 327-331). In addition, a suspension of payments from the banking system effectively requires commitment from multiple branches of government, which can be especially difficult to achieve. The executive branch in Argentina, for example, could not prevent the court system from allowing additional withdrawals after the deposit freeze was declared. These institutional features that undermine a government's ability to pre-commit to a given course of action create precisely the type of situations we aim to draw attention to with our analysis.

The issues we have highlighted here are also relevant for analyzing runs on non-bank financial institutions and investment funds. In some cases, our analysis can be applied directly. Moneymarket and related funds, for example, closely resemble the banks in our model. These funds typically invest in relatively liquid assets, but disruptions in financial markets can cause their assets to become considerably less liquid. Such funds can (and do) respond to a run by temporarily suspending investor redemptions and rescheduling payments. Our analysis suggests that the sus- 
ceptibility of such funds to a run could depend, in large part, on details of the expected response and the ex ante incentives this response gives to investors.

More generally, a range of financial institutions rely on short-term funding in money markets while holding long-term, illiquid assets. The recent period of financial turmoil has witnessed a variety of events that resembled a run on such institutions. Beginning in August 2007, for example, many firms that had previously been able to issue short-term debt in the form of commercial paper suddenly found that they could not roll over this debt; investors seemed to "run" away from this market. Another example was the near-collapse of the U.S. investment bank Bear Stearns in March 2008, which Barry Eichengreen described as being "a lot like a 19th-century run on the bank.”20 The specific features of these types of events may differ from those in our model; for example, the policy options available to a government or central bank may depend on the type of institution(s) experiencing a run. Nevertheless, we believe it is again critical in these cases to study how the losses caused by a run will be distributed ex post and what ex ante incentives the policy response creates. A logical starting point for any such analysis is to focus on the allocation of resources that the interested parties will find to be ex post efficient, as we do here.

As a final remark, we note that our analysis may also be useful for studying phenomena in asset markets. Observers often claim that certain episodes in these markets are analogous to a bank run; examples include the stock market crash in 1987, the "mini-crash" in 1997 and, more recently, the breakdown of the market for auction-rate securities in early 2008. Bernardo and Welch [3] and Morris and Shin [26] have provided important first steps in developing models of this type of market fragility. Major disruptions in asset markets often trigger some kind of policy response, such as temporarily halting trade on an exchange. We believe that studying the effects of ex post interventions on ex ante incentives, as we have done here, is likely to provide critical insights into the potential sources of instability in these settings as well.

20 New York Times, “Depression, You Say? Check Those Safety Nets,” March 23, 2008. 


\section{Appendix A. Proof of Proposition 2}

The banking system is fragile if and only if the efficient freeze point $\pi_{s}^{M}$ is greater than or equal to the threshold $\pi^{T}$ identified in Lemma 1. Under Assumption 1, the function $c_{L}\left(\pi_{s}\right)$ defined in (5) is strictly concave. Since the utility function $u$ is also strictly concave, the objective function (4) is a strictly concave function of $\pi_{s}$. Fragility obtains, therefore, if and only if $W^{\prime}\left(\pi^{T}\right) \geq 0$ holds. The derivative of the objective function is given by

$$
W^{\prime}\left(\pi_{s}\right)=u\left(c_{E}^{*}\right)-(1-\pi) u\left[c_{L}\left(\pi_{s}\right)\right]+\left(1-\pi_{s}\right)(1-\pi) u^{\prime}\left[c_{L}\left(\pi_{s}\right)\right] \frac{d c_{L}\left(\pi_{s}\right)}{d \pi_{s}}
$$

where, from (5), we have

$$
\frac{d c_{L}\left(\pi_{s}\right)}{d \pi_{s}}=\frac{R}{1-\tau} \frac{1}{(1-\pi)\left(1-\pi_{s}\right)^{2}}\left(1-\tau i^{*}-c_{E}^{*}\right) .
$$

Combining these two expressions and simplifying yields

$$
W^{\prime}\left(\pi_{s}\right)=u\left(c_{E}^{*}\right)-(1-\pi) u\left[c_{L}\left(\pi_{s}\right)\right]+u^{\prime}\left[c_{L}\left(\pi_{s}\right)\right] \frac{R}{1-\tau} \frac{\left(1-\tau i^{*}-c_{E}^{*}\right)}{\left(1-\pi_{s}\right)} .
$$

Suppose we evaluate this derivative at the threshold point $\pi^{T}$, which is defined by the condition $c_{L}\left(\pi^{T}\right)=c_{E}^{*}$. Then we have

$$
W^{\prime}\left(\pi^{T}\right)=\pi u\left(c_{E}^{*}\right)+u^{\prime}\left(c_{E}^{*}\right) \frac{R}{1-\tau} \frac{\left(1-\tau i^{*}-c_{E}^{*}\right)}{\left(1-\pi^{T}\right)} .
$$

Solving the equation $c_{L}\left(\pi^{T}\right)=c_{E}^{*}$ for $\pi^{T}$ yields

$$
\pi^{T}=\frac{\frac{R}{1-\tau}\left(1-\tau i^{*}\right)-(1-\pi) c_{E}^{*}}{\frac{R}{1-\tau} c_{E}^{*}-(1-\pi) c_{E}^{*}}
$$

which can be rewritten as

$$
\frac{R}{1-\tau} \frac{c_{E}^{*}-\left(1-\tau i^{*}\right)}{\left(1-\pi^{T}\right)}=c_{E}^{*}\left[\frac{R}{1-\tau}-(1-\pi)\right] .
$$

Substituting this expression into (12) yields

$$
\begin{aligned}
W^{\prime}\left(\pi^{T}\right) & =\pi u\left(c_{E}^{*}\right)-u^{\prime}\left(c_{E}^{*}\right) c_{E}^{*}\left[\frac{R}{1-\tau}-(1-\pi)\right] \\
& =u\left(c_{E}^{*}\right)\left(\pi-\frac{u^{\prime}\left(c_{E}^{*}\right) c_{E}^{*}}{u\left(c_{E}^{*}\right)}\left[\frac{R}{1-\tau}-(1-\pi)\right]\right) .
\end{aligned}
$$

This final expression show that $W^{\prime}\left(\pi^{T}\right) \geq 0$ holds, and hence the banking system is fragile, if and only if (6) holds. 


\section{References}

[1] Allen, Franklin and Douglas Gale, “Optimal financial crises,” Journal of Finance 53 (1998), 1245-1284.

[2] Angeletos, George-Marios and Ivan Werning, "Crises and Prices: Information Aggregation, Multiplicity, and Volatility,” American Economic Review 96 (2006), 1720-1736.

[3] Bernardo, Antonio E. and Ivo Welch, “Liquidity and Financial Market Runs,” Quarterly Journal of Economics 119 (2004), 135-158.

[4] Calomiris, Charles W. and Joseph R. Mason, "Contagion and bank failures during the great depression: The June 1932 Chicago banking panic,” American Economic Review 87 (1997), 863-883.

[5] Calomiris, Charles W. and Joseph R. Mason, "Fundamentals, panics and bank distress during the depression,” American Economic Review 93 (2003), 1615-1647.

[6] Carlsson, Hans and Eric van Damme, “Global Games and Equilibrium Selection,” Econometrica 61 (1993), 989-1018.

[7] Chari, V.V. and R. Jagannathan, "Banking Panics, Information, and Rational Expectations Equilibrium,” Journal of Finance 43 (1988), 749-761.

[8] Cooper, Russell and Thomas W. Ross, "Bank runs: liquidity costs and investment distortions," Journal of Monetary Economics 41 (1998), 27-38.

[9] Cooper, Russell and Thomas W. Ross, "Bank Runs: Deposit Insurance and Capital Requirements,” International Economic Review 43 (2002), 55-72.

[10] Diamond, Douglas W. and Phillip H. Dybvig, "Bank runs, deposit insurance, and liquidity," Journal of Political Economy 91 (1983), 401-419.

[11] Diamond, Douglas W. and Raghuram G. Rajan, "Money in a theory of banking," American Economic Review 96 (2006), 30-53.

[12] Dominguez, Kathryn M. E. and Linda L. Tesar, "International borrowing and macroeconomic performance in Argentina," in Capital Controls and Capital Flows in Emerging Economies: Policies, Practices, and Consequences, edited by Sebastian Edwards, University of Chicago Press for the NBER, forthcoming (2006).

[13] Engineer, Merwan, "Bank runs and the suspension of deposit convertibility,” Journal of Monetary Economics 24 (1989), 443-454.

[14] Ennis, Huberto M., “Economic Fundamentals and Bank Runs,” Federal Reserve Bank of Richmond Economic Quarterly 89 (2003), 55-71.

[15] Ennis, Huberto M. and Todd Keister, “Government policy and the probability of coordination failures,” European Economic Review 49 (2005), 939-973.

[16] Ennis, Huberto M. and Todd Keister, “Bank runs and investment decisions revisited,” Journal of Monetary Economics 53 (2006), 217-232. 
[17]Ennis, Huberto M. and Todd Keister, “Commitment and Equilibrium Bank Runs,” Federal Reserve Bank of New York Staff Report No. 274 (2007).

[18]Friedman, Milton and Anna Jacobson Schwartz, A Monetary History of the United States, 1867-1960. Princeton University Press (1963).

[19] Goldstein, Itay and Ady Pauzner, "Demand deposit contracts and the probability of bank runs,” Journal of Finance 60 (2005) 1293-1327.

[20] Gorton, Gary, “Bank suspension of convertibility,” Journal of Monetary Economics 15 (1985), 177-193.

[21] Green, Edward J. and Ping Lin, “Diamond and Dybvig's classic theory of financial intermediation: What's missing?” Federal Reserve Bank of Minneapolis Quarterly Review 24 (2000), 3-13.

[22] International Monetary Fund, "Sovereign Debt Restructurings and the Domestic Economy. Experience in Four Recent Cases,” prepared by the Policy Development and Review Department, February 2002.

[23] Kaminsky, Graciela L. and Carmen M. Reinhart. "The Twin Crises: The Causes of Banking and Balance-Of-Payments Problems,” American Economic Review 89 (3) (June 1999) 473500 .

[24]King, Robert G., "Discretionary policy and multiple equilibria,” Federal Reserve Bank of Richmond Economic Quarterly 92 (2006), 1-15.

[25] Kydland, Finn E. and Edward C. Prescott, "Rules rather than discretion: the inconsistency of optimal plans,” Journal of Political Economy 85 (1977), 473-492.

[26] Morris, Stephen and Hyun Song Shin, “Liquidity Black Holes,” Review of Finance 8 (2004) $1-18$.

[27] Peck, James and Karl Shell, “Equilibrium bank runs,” Journal of Political Economy 111 (2003), 103-123.

[28] Villamil, Anne, "Demand deposit contracts, suspension of convertibility, and optimal financial intermediation,” Economic Theory 1 (1991), 277-288.

[29] Wallace, Neil. "Another attempt to explain an illiquid banking system: the Diamond and Dybvig model with sequential service taken seriously," Federal Reserve Bank of Minneapolis Quarterly Review 12 (Fall 1988), 3-16. 